\title{
Can XRF scanning of speleothems be used as a non-destructive method to identify paleoflood events in caves?
}

\author{
Martin Finné ${ }^{1,2,3^{*}}$, Malin Kylander ${ }^{3,4}$, Meighan Boyd ${ }^{1,2,3}$, Hanna S. Sundqvist ${ }^{1,3}$, \\ and Ludvig Löwemark ${ }^{5}$ \\ ${ }^{1}$ Department of Physical Geography and Quaternary Geology, Stockholm University, 10691 Stockholm, Sweden \\ ${ }^{2}$ Navarino Environmental Observatory (NEO), Messina, Greece \\ ${ }^{3}$ Bolin Centre for Climate Research, Stockholm University \\ ${ }^{4}$ Department of Geological Sciences, Stockholm University, 10691 Stockholm, Sweden \\ ${ }^{5}$ Department of Geosciences, National Taiwan University, 106 Taipei, Taiwan
}

\begin{abstract}
We have developed a novel, quick and non-destructive method for tracing flood events in caves through the analysis of a stalagmite thick section with an XRF core scanner. The analyzed stalagmite has multiple horizons of fine sediments from past flood events intercalated with areas of cleaner calcite. Flood events detected from the elemental XRF core scanning data show good agreement with the position of flood horizons identified in petrographic thin sections. The geochemical composition of the individual flood layers shows that in certain cases the clay horizons had a distinct geochemical fingerprint suggesting that it may be possible to distinguish individual flood layers based on their geochemistry. This presents the possibility for using flood events as marker horizons to chronologically tie different speleothems in a cave to each other.
\end{abstract}

Keywords: $\quad$ stalagmite; floods; XRF core scanning; elemental data; Southern Greece

Received 20 May 2014; Revised 26 August 2014; Accepted 28 August 2014

Citation: $\quad$ Finné M., Kylander M., Boyd M., Sundqvist H.S. and Löwemark L., 2014. Can XRF scanning of speleothems be used as a non-destructive method to identify paleoflood events in caves? International Journal of Speleology, 44 (1), 17-23. Tampa, FL (USA) ISSN 0392-6672 http://dx.doi.org/10.5038/1827-806X.44.1.2

\section{INTRODUCTION}

Caves have been, or are, an integral part of the hydrological system in karstic areas. Relict cave systems (abandoned by flowing water) often act as sediment traps, with silts and clays transported in suspension being the most common allogenic deposits (Ford \& Willams, 1989). Fine sediments carried into a cave by water mostly accumulate on cave floors. In the Mediterranean realm the allogenic input of e.g. reworked soils is a common phenomenon in karst caves (Lewin \& Woodward, 2009). Water entering a relict cave can often be related to flooding, especially in areas where high recharge events occur and the position of the cave is close to the modern water table (Palmer, 1991; Dorale et al., 2005). Traces of cave floods in the form of detrital layers have been recorded in speleothems in a number of caves. For instance, Borsato et al. (2003) found thin veils of silt and clay intercalated with the carbonates of a speleothem found in northern Italy. The usefulness of detrital layers in speleothems as recorders of flooding history has been shown by Dorale et al. (2005) and Dasgupta et al. (2010) by analyzing speleothems from two North American caves, prompting us to further investigate this field using new methods.

Over the past decade X-ray fluorescence (XRF) core scanning has been increasingly utilized in paleoclimate studies. XRF core scanning has the advantage in that it can provide high-resolution (submillimeter) elemental data, as well as radiographic and optical images. This XRF technique requires a minimum of sample preparation - only a flat surface is demanded - and the analysis itself is fast and non-destructive. This method has provided a wealth of data for both marine (e.g., Riethdorf et al., 2013) and lake sediment (e.g., Kylander et al., 2011) sequences. While the analysis of sediment cores is well established, further applications remain to be developed. In theory, all elements with atomic numbers between $\mathrm{Al}$ and $\mathrm{U}$ can be measured as long as the material has a flat surface. In practice however there are issues that can arise if the matrix is too crystalline, causing diffraction peaks, or if the matrix is dominated by a single element (Croudace et al., 2006). This is the case with speleothems where $\mathrm{Ca}$ concentrations overwhelm the signal causing sum peaks in the produced spectra. This makes it difficult 
to observe changes in the calcite matrix itself. There are however, some examples of successful applications of XRF scanning to speleothems. These include both micro-XRF analyzes and XRF core scanning to detect variations in trace elements in the calcite matrix (Frisia et al., 2005; Borsato et al., 2007; Dandurand et al., 2011; Cui et al., 2012; Wu et al., 2012). In the case of speleothems that have archived flood layers, the high Ca concentrations of the matrix become an advantage as the contrasting non-calcite signal becomes very easy to locate.

In this paper we investigate whether XRF core scanning can detect layers containing fine sediment particles in a thick section of a stalagmite and thus can be used as a quick, non-destructive method, in the sense that only a cut surface is needed, to detect flooding events in speleothems. We also analyze the geochemical properties of the individual clay horizons to assess the potential for extracting information from these layers.

\section{MATERIAL AND METHODS}

\section{Setting and sample description}

Kapsia Cave $\left(\mathrm{N}^{\circ} 7^{\circ} 37^{\prime}, \mathrm{E} 22^{\circ} 22^{\prime}\right)$ is located on the western perimeter of the Mantinea plain in central Peloponnese, southern Greece (Fig. 1). The natural entrance to the cave is located at roughly the same level as the plain floor approximately $20 \mathrm{~m} \mathrm{SSW}$ of one of the five sinkholes draining the plain (Higgins \& Higgins, 1996, see Fig. 1). When surface water inputs exceed the draining capacity of these sinkholes, the Mantinea plain, or parts of the plain, will experience flooding. The sinkholes are typically blocked every 2-3 years, at least for the period 1950-1991, and sometimes water levels are sufficient to flood the cave (Liakopoulos, pers. comm.; Merdenisianos, 2005). The latest major flood affecting the plain and the cave was recorded in 2001 (Rousiotis, pers. comm.). The cave floor is covered by fine, clayey, sediments carried into the cave from the adjacent plain by floodwater. In Kapsia Cave a clear high-water flood mark can be seen on the walls throughout the cave, in areas above this mark clayey sediments are not present indicating that they are mainly transported by water.

Stalagmite GK0901 was collected in 2009. The height of the stalagmite was c. $270 \mathrm{~mm}$ and it was conically shaped. Its position at a level similar to the natural entrance increases the likelihood of capturing flooding events in the selected sample (Fig. 1). A one centimeter thick central slab was cut parallel to the growth axis of the stalagmite. Along the growth axis powder for stable isotope analysis (not performed) and U-Th dating was extracted, resulting in cavities.

Clay samples were collected from the floor at three different positions in proximity to the collected stalagmite. Clay samples were dried at room temperature and ground to a fine powder. One clay sample was treated with $\mathrm{HCl}$ in order to remove carbonates to investigate the potential effect of precipitated calcite on or in the clay after it was deposited on the cave floor.

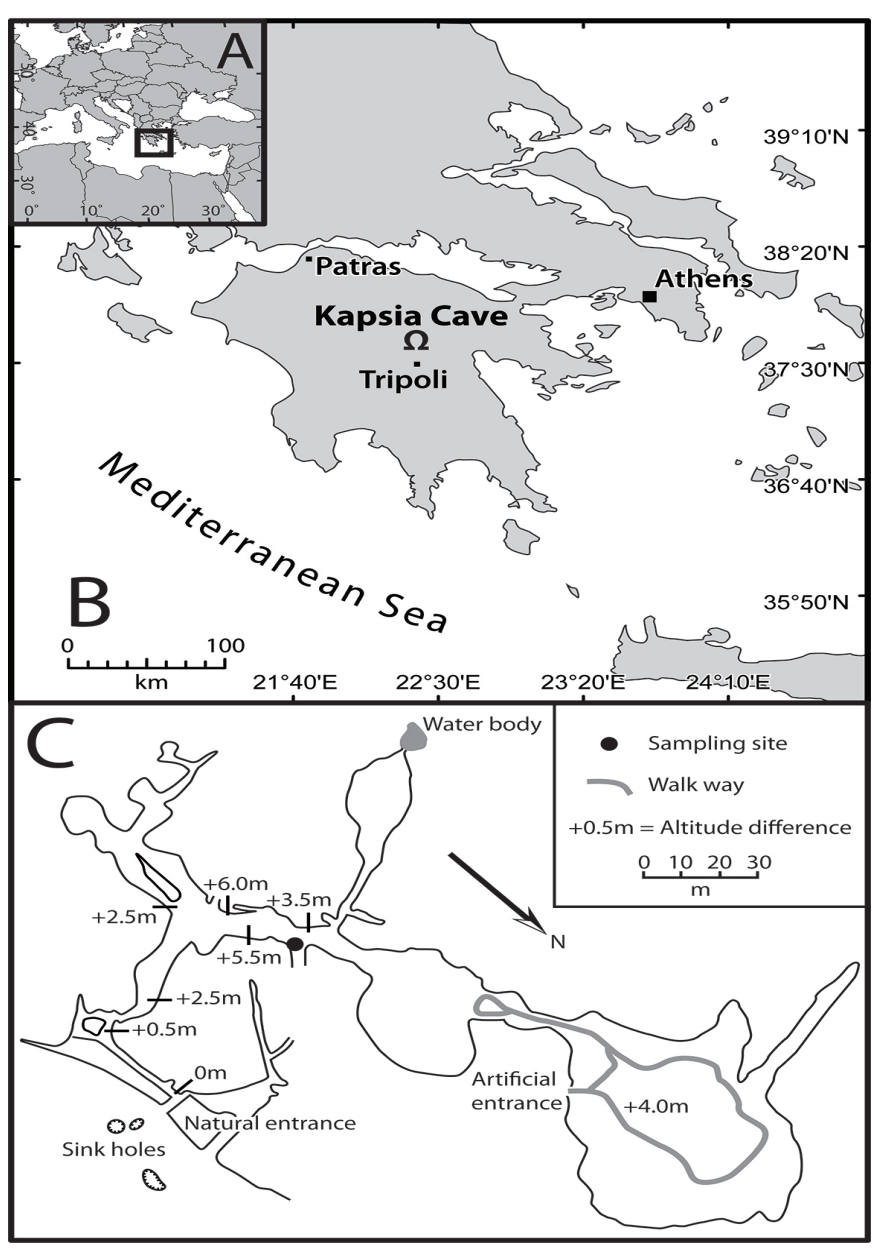

Fig. 1. A. Map A, overview map; B. Map B, location of Kapsia Cave on the Peloponnese; C. Map C, layout of Kapsia Cave. Altitudinal differences in the map are after Merdenisianos (2005). Note that the sampling location is lower than indicated by the nearest altitudinal value as it was collected in an almost vertical tunnel. The sampling location is at a relatively low position in the cave.

\section{U-Th dating}

Six samples for U-Th dating were milled at different levels in the stalagmite (Fig. 2). However, low levels of $\mathrm{U}(<0.378 \mathrm{ppm})$ and high levels of detrital thorium, as indicated by very low $\left({ }^{230} \mathrm{Th} /{ }^{232} \mathrm{Th}\right)(<6.90)$, meant that no reliable $\mathrm{U}-\mathrm{Th}$ results could be retrieved.

\section{XRF scanning}

The polished thick section was scanned using an ITRAX XRF core scanner from Cox Analytical Systems (Gothenburg, Sweden) located at the Department of Geological Sciences, Stockholm University, along the non-uniform central growth axis. A Mo tube set at $30 \mathrm{kV}$ and $30 \mathrm{~mA}$ was used and the scanning was made at a step size of $200 \mu \mathrm{m}$ and an exposure time of $40 \mathrm{~s}$. The scanning produces a digital optical RBG image, a digital radiographic image, and a $\mu$-XRF elemental profile. Three separate scans with some overlap were performed in order to produce an accurate trace element profile of the full central growth axis, which has shifted over time (Fig. 2). The three separate sections were pieced together into one series for the whole stalagmite using XRF elemental data for $\mathrm{Fe}$ and $\mathrm{Ti}$ in the overlapping areas.

Dried clay samples were loaded into open plastic containers, placed on a custom built tray and scanned with the same settings as described above. 


\section{Thin sections}

Eight petrographic thin sections were produced from the facing side of the scanned surface (Fig. 2). The petrographic thin sections were analyzed for clay horizons under Nikon
Optiphot 2-Pol under x25 and x100 magnification in both plane-polarized light and crossed polarized light. Additionally the thin sections were scanned in $1200 \mathrm{dpi}$ resolution and inspected for clay horizons.
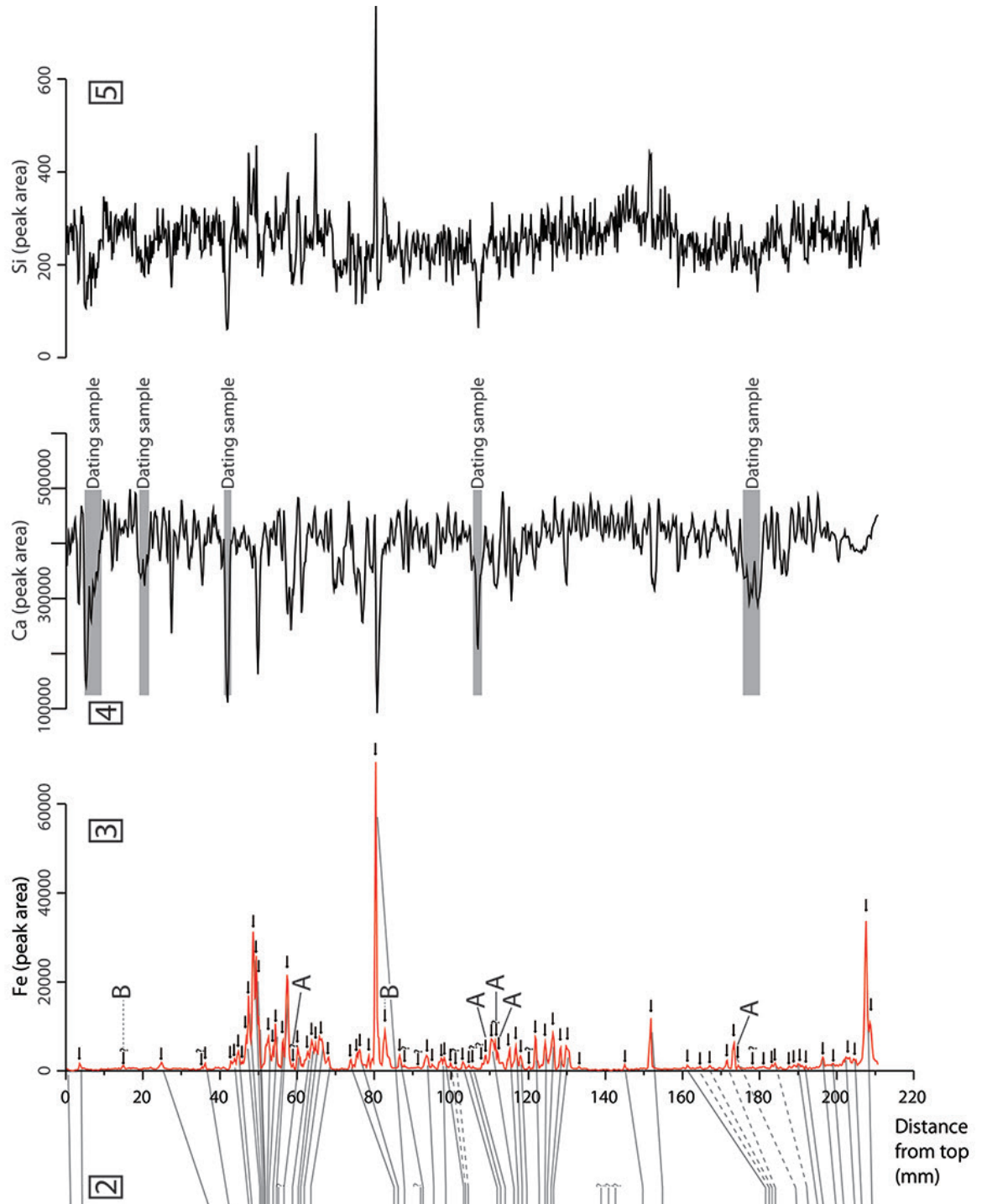

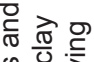

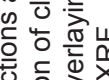

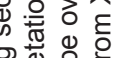

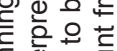

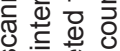

ᄂ

등

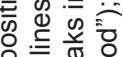

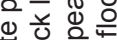

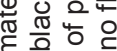

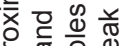

응

政

要

这敦西

这旁

这

는

증 욜 응

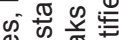

o.

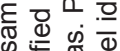

들

흥

응

क N 0 중

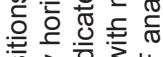

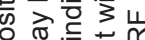

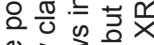

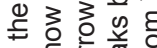

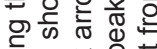

妾

政

\& $\Phi$.

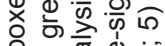

ब施施

等

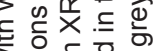

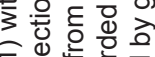

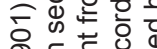

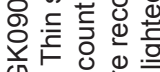

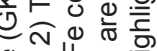

这整焉

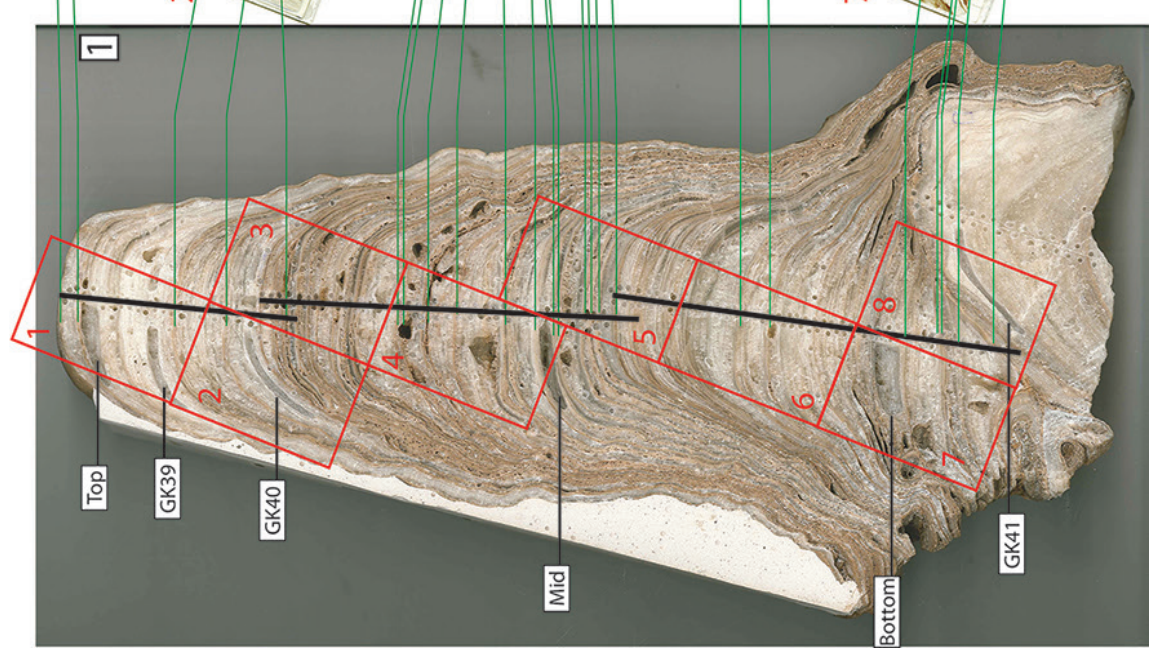

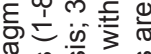

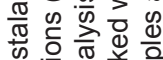

ᄂ

등.

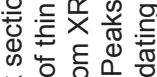

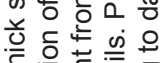

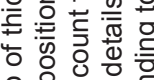

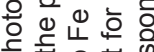

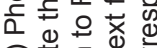

西

进 证

है

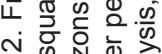

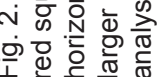




\section{RESULTS AND DISCUSSION}

\section{Analytical quality}

$\mathrm{X}$-ray fluorescence from speleothems gives a strong signal due to their dense nature in comparison to e.g. the lake and marine sediments normally analyzed in the XRF core scanner. The main challenge with analyzing a calcite matrix using XRF core scanning is the generation of Ca sum peaks in the spectra and adjusting the peak fitting during processing to account for this (Brouwer, 2006). Sum peaks are generated when two photons arrive at the detector at the same time and are counted as a single photon. In the case of $\mathrm{Ca}$ which has a $\mathrm{K}_{\mathrm{a}}$ line at $3.69 \mathrm{keV}$ and $\mathrm{K}_{\beta}$ line at 4.01 , the sum peaks are generated at $7.38\left(\mathrm{~K}_{\mathrm{a}}+\mathrm{K}_{\mathrm{a}}\right), 7.70\left(\mathrm{~K}_{\mathrm{a}}+\mathrm{K}_{\beta}\right)$ and 8.02 $\left(\mathrm{K}_{\beta}+\mathrm{K}_{\beta}\right)$ (Fig. 3). Extra lines must be added during peak fitting to account for these sum peaks. The goodness of fit between measured spectra and theoretical spectra during processing is assessed by the mean standard error (MSE). Peak fitting during processing was made in the upper part of the sample which has relatively pure calcite. Therefore the profile of MSE versus depth for the Kapsia speleothem shows the lowest values (i.e. the best fit) in the most pure calcite sections. Increased MSEs are often observed where there is a drop in the counts per second; these decreases are a product of the grooves and gaps produced by the presence of the flood layers (for details see discussion about washing effect below) and cavities from sampling. Despite the analytical challenges associated with this type of sample, good counting statistics were acquired for multiple elements including $\mathrm{Si}, \mathrm{K}, \mathrm{Ti}, \mathrm{Ca}, \mathrm{Fe}, \mathrm{Sr}$, and $\mathrm{Zr}$.
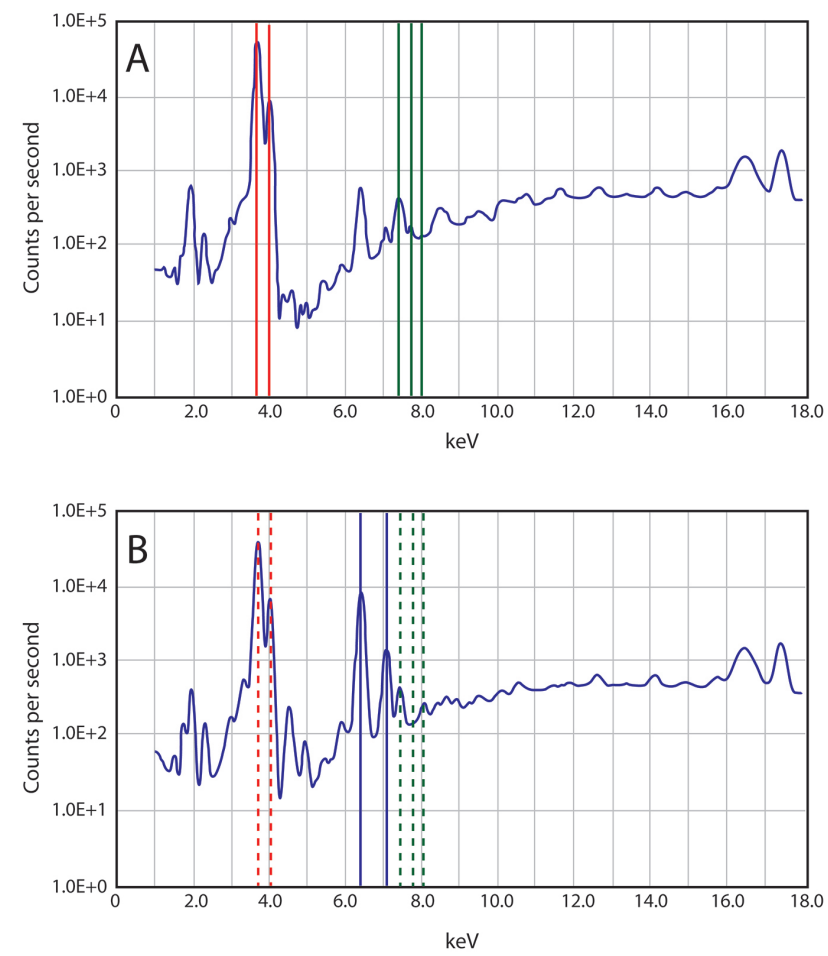

Fig. 3. A. Smoothed XRF spectra from pure calcite showing Ca peaks (indicated by red bars) and Ca sum (green bars) peaks, generated by two photons arriving at the detector simultaneously. Ca lines are located at $3.69 \mathrm{keV}\left(\mathrm{K}_{\alpha}\right)$ and $4.01 \mathrm{keV}\left(\mathrm{K}_{\mathrm{B}}\right)$ while the Ca sum peaks are found at $7.38 \mathrm{keV}\left(\mathrm{K}_{\alpha}+\mathrm{K}_{\alpha}\right), 7.70 \mathrm{keV}\left(\mathrm{K}_{\alpha}+\mathrm{K}_{\beta}\right)$ and $8.02 \mathrm{keV}\left(\mathrm{K}_{\beta}+\mathrm{K}_{\beta}\right)$; B. Smoothed XRF spectra from clay layer showing Fe peaks at 6.39 and $6.40 \mathrm{keV}\left(\mathrm{K}_{\alpha}\right)$ and $7.06 \mathrm{keV}\left(\mathrm{K}_{\beta}\right)$ (blue bars). The two $\mathrm{Ka}$ are read as one by the detector type used. The Ca signal from the matrix is still detectable indicated by dashed red and green bars (same as in A)

\section{Flood horizons as revealed by XRF scanning} and petrographic thin sections

The polished thick section of the stalagmite shows alternating intervals of clean white calcite and thin horizons containing brown sediments (Fig. 2). The sediment horizons are roughly the same color as the clay found on the cave floor. From this fact, together with the knowledge that floods have occurred and drawing on previous research from other caves (Dorale et al., 2005; Dasgupta et al., 2010), we infer that these clayey horizons derive from past floods. Since the stalagmite contains multiple flood horizons of varying thickness it is a highly suitable sample to investigate how well the XRF core scanner can identify flood events and to analyze and compare geochemical properties of individual layers.

The alignment of the three separate scan paths was straightforward as the multiple flood horizons yielded distinct elemental patterns. However, in cases where a scanned specimen does not contain as many flood horizons as the sample studied here, the alignment of separate scans might prove more difficult. This could be overcome by adding artificial marker horizons in the form of e.g. a thin metal wire producing a distinctive signal at two or more levels in the tracks that are to be aligned.

XRF elemental data from the stalagmite thick section show large variability in a number of elements e.g. Fe, $\mathrm{Si}$, Ti, and $\mathrm{Ca}$ (Fig. 2). The results from the three cave clay samples show elevated peak area values for e.g. $\mathrm{Fe}, \mathrm{K}, \mathrm{Si}$, Ti, and $\mathrm{Zr}$ compared to the calcite matrix (Fe and Si shown in Fig. 4). Visually clean areas of the stalagmite consisting of mainly white opaque and/ or translucent darker calcite show small peak area values of elements associated with clays. In areas where clay horizons are present elevated peak areas of clay elements are recorded while reduced $\mathrm{Ca}$ peak areas occur (Fig. 2). Calcium peak areas also decrease in sections where dating samples have been extracted and in places where the XRF beam has passed over cavities in the calcite matrix.

By comparing elemental data from the thick section and the cave clay samples we suggest that $\mathrm{Fe}$ and $\mathrm{Si}$ are suitable elements to identify flood events in the stalagmite. Both elements are present in lower amounts in the calcite matrix and higher amounts in the clay samples (Fig. 4). We chose to focus on fluctuations in Fe counts from the XRF core scanner as a proxy for flood events because Fe has a strong signal-to-concentration ratio, making it detectable even in small amounts.

From the Fe-signal we identify 3 different peak types: major, medium and minor peaks, based on differences in the strength of the elemental signal (i.e. the magnitude of the peak), along with a base line value representing the calcite matrix. We use the center of each elemental increase, i.e. the highest values in that increase, to define the peak types (Table I).

The Fe peak area versus depth profile shows 81 peaks of variable size along the stalagmite growth axis (Fig. 2). The analysis of the petrographic thin sections revealed 62 clay horizons of variable thicknesses in the Kapsia Cave stalagmite (Fig. 2). There is a good 


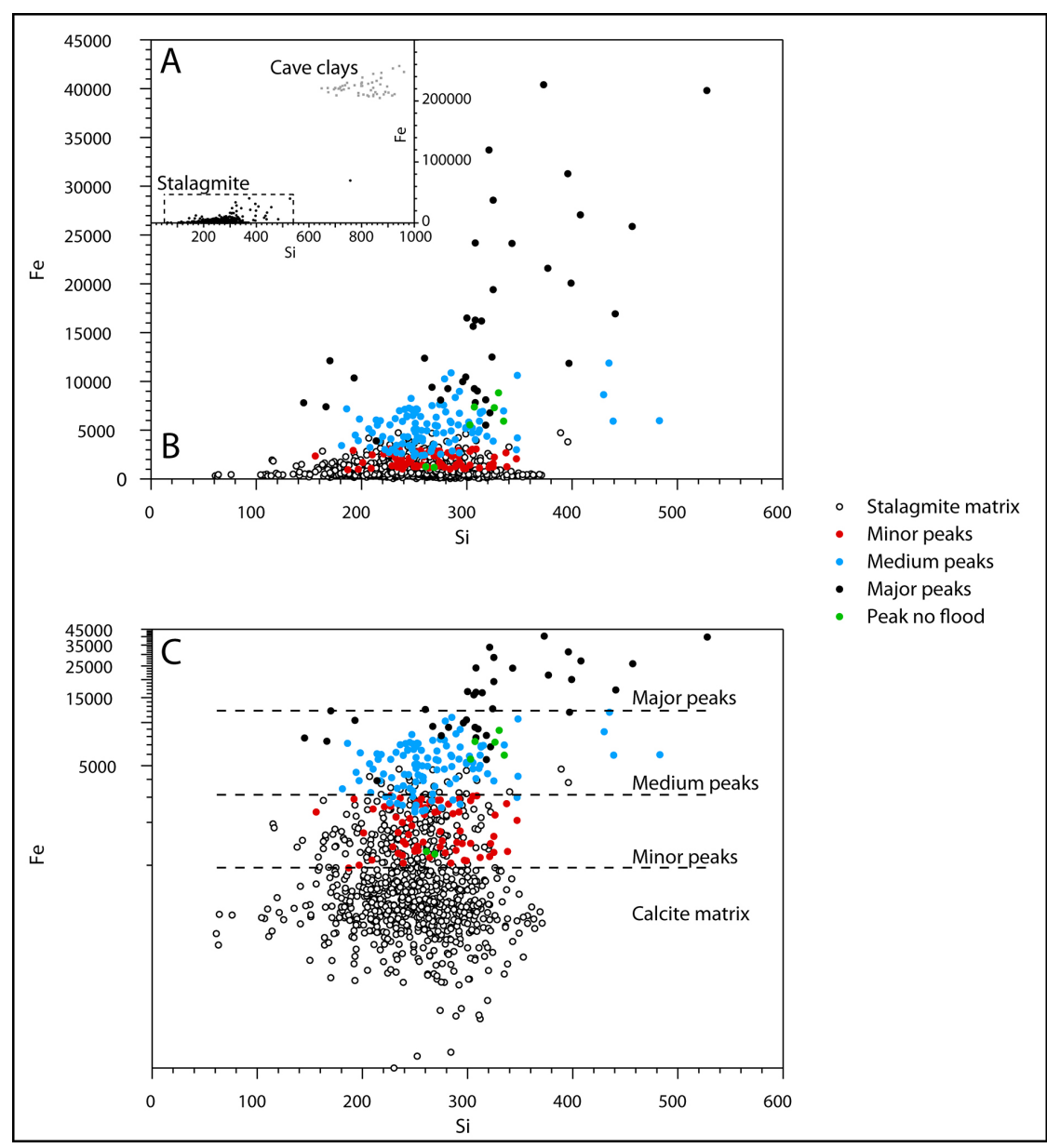

Fig. 4. A. Biplots (Fe vs $\mathrm{Si}$ ) of stalagmite clays together with stalagmite values (both clayey layers and matrix) showing the difference in the signal between cave clay samples and the stalagmite. The dashed box indicates the area of zoom in B and C; B. Biplots (Fe vs Si) of stalagmite clays and calcite matrix. Revealing a clustering that closely follows the different peak types (major, medium and minor peaks) presented in Table I. All values in peak areas; C. Biplots ( $\mathrm{Fe}$ vs $\mathrm{Si}$ ) of stalagmite clays and calcite matrix same as in B but on a logarithmic $y$-axis highlighting how close the clustering follows the different identified peak types (major, medium and minor peaks). Intervals, marked by horizontal black bars, follow values in

Table I. It can also be seen that calcite matrix values are distinctly different from the clayey horizons. All values in peak areas.

Table 1. Peak area values defining the different peak types and the speleothem matrix. All values reported in peak areas. *In some instances higher counts on either the increasing or the decreasing. side of a peak have been considered to belong to the matrix.

\begin{tabular}{|c|c|c|}
\hline Type & Interval & Average \\
\hline Major peaks & $\geq 12000$ & 17817 \\
\hline Medium peaks & $\geq 3100<12000$ & 5252 \\
\hline Small peaks & $\geq 959<3100$ & 1915 \\
\hline Matrix & $<959 *$ & 894 \\
\hline
\end{tabular}

agreement between the position of flood horizons identified in the thin sections and the elemental $\mathrm{Fe}$ data with 59 of $81 \mathrm{Fe}$ peaks ascribed to a flood horizon identified in the thin sections.

Discrepancies between the thin section and XRF core scanning methods can be explained by three factors. Firstly, considering the mismatch between total $\mathrm{Fe}$ peaks $(n=81)$ and Fe peaks ascribed to a flood horizon $(n=59)$, we note that several of the Fe peaks (17 of the deviating 22) signaling flood events are actually smaller peaks overlaying a larger peak (as shown for example at those depths marked with A in Fig. 2). These most likely correspond to a single clay horizon identified in the thin sections or to a generally clayey area. We attribute this to a washing effect which sees the loss of clay particles and the creation of a micro-undulating surface, especially in thicker clay layers. The washing effect is related to loss of clay material while cutting the sample using a diamond saw cooled and lubricated by water. The XRF-core scanner integrated a signal across a less cohesive material causing more scattered secondary X-rays to be emitted. The remaining 5 peaks (of the deviating 22) that have not been ascribed to a flood horizon are barely separable from the base line Fe values.

Secondly, there are two instances where there is a Fe-signal peak but no flood level identified in the thin sections (referred to as "peak no flood"), in the interval 82.4 to $83.2 \mathrm{~mm}$ from the top and in the interval 14.8 to $15.0 \mathrm{~mm}$ from the top (Fig. 2, marked with B). In the former case there are multiple clay horizons in close proximity to the Fe peak, making it difficult to exactly match this peak to a certain flood level. In the latter case it is difficult to find a satisfactory explanation.

Thirdly, the three "missing" clay horizons, i.e. the ones identified in the thin sections but not found in the $\mathrm{Fe}$ peak area profile (62-59), are visible in the thin sections around $140 \mathrm{~mm}$ from the top but have no counterpart in the $\mathrm{XRF}$ elemental signal. There is also one clay layer close to the stalagmite top (at ca. $0.05 \mathrm{~cm}$ depth), which is not seen as a discrete peak in the Fe-signal but rather as a slight increase in Fe peak area. From the thin section analysis it is not evident that these horizons are unusually faint or thin compared to other recorded flood layers. The inability of the core scanner to identify these layers may be related to the geometry of the X-ray beam vs. the not perfectly horizontal clay horizons in the stalagmite. A bleeding effect results if the X-ray beam hits a calcite/clay boundary at an angle and therefore records the signal of both layers. Because the width of the detection footprint is about $8 \mathrm{~mm}$ wide and $0.2 \mathrm{~mm}$ thick, any oblique layers may be "smeared" and almost disappear from the record if they are thin enough.

\section{Geochemical composition of individual clay horizons}

In order to investigate the geochemical properties of the individual clay horizons, elemental biplots of $\mathrm{Fe}$ vs. Si, two elements with stronger peak areas in both the cave and stalagmite clays, were produced. The biplots reveal a pattern of clusters that to a large extent mirror the previously established peak types (major, medium, minor and "peak no flood") and matrix values (Fig. 4). There is still a substantial 
discrepancy between the geochemical composition of the cave and stalagmite clays. The difference in the strength of the signal between the cave clay samples and stalagmite clays, presumably consisting of the same material, can be attributed to the washing effect, or the bleeding effect, (both outlined above), or the fact that clay layers in the speleothems most likely are intermixed with calcite crystals creating a different signal. The pure clay samples are also different in terms

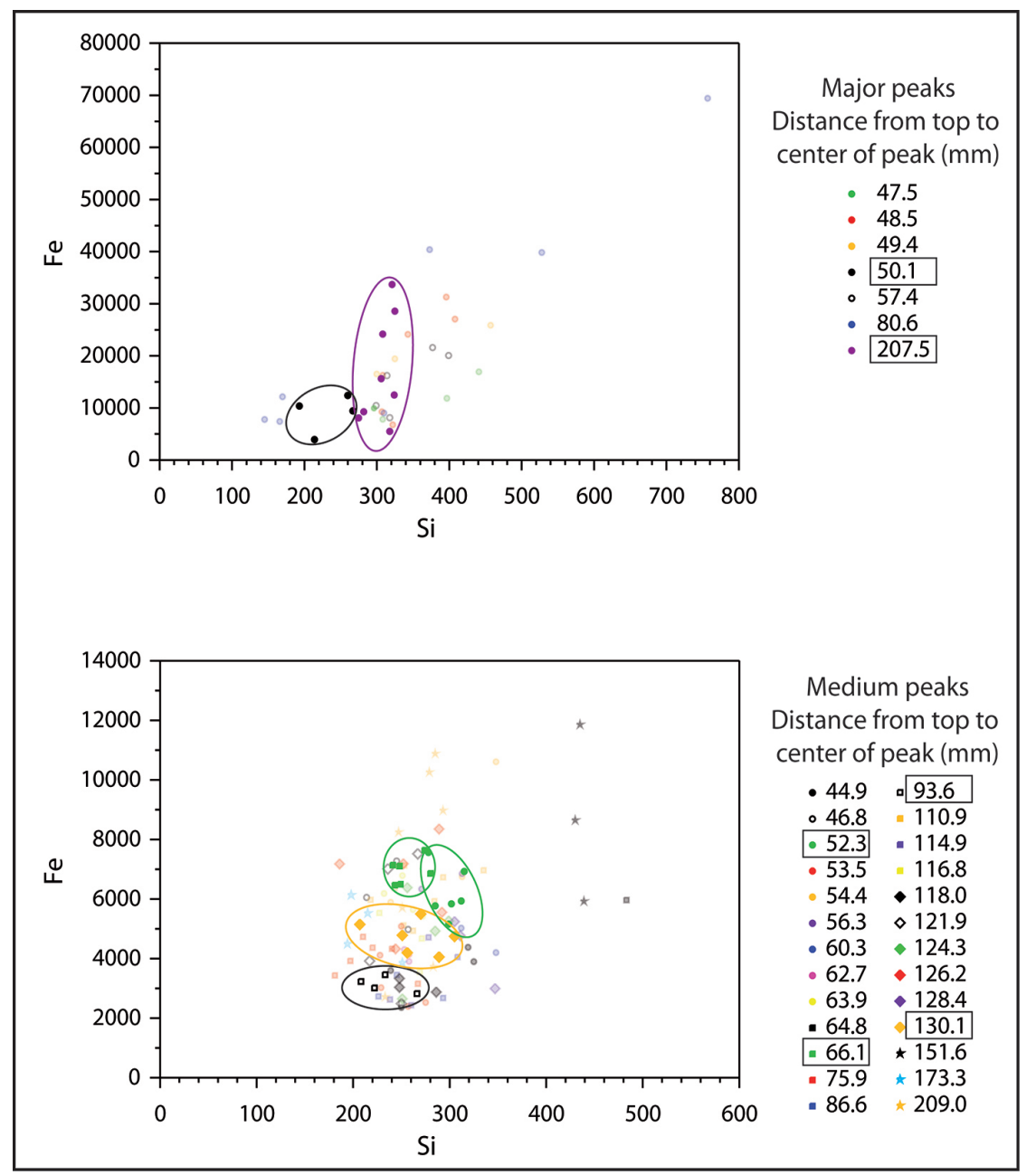

Fig. 5. Individual biplots of individual flood horizons for major peaks (upper plot) and medium peaks (lower plot). Numbers in legends refer to the distance from the top of the center point of the peak. Clustering is evident for some of the individual flood horizons indicating a distinct geochemical signal for instance for peaks at: 50.1 and $207.5 \mathrm{~mm}$ in upper plot and at: 52.3, 66.1, 93.6, and $130.1 \mathrm{~mm}$ in the lower plot - all enclosed by boxes.

of homogeneity compared to the speleothem. Variations in sedimentation of different fractions of the suspended sediments on the stalagmite compared to the cave floor could also have an effect on the signal.

A closer inspection of the geochemistry of the individual clay horizons in the biplots reveals a distinct geochemical pattern of the separate layers (Fig. 5). This suggests that it is possible to distinguish individual flood layers based on their geochemistry. This presents a possibility for using a geochemically distinct individual flood layer as a marker horizon for multiple speleothems from a cave creating a way to chronologically tie them together, much in a similar way as tephra layers may be utilized for sediments (e.g. Lowe, 2011; Kylander et al., 2012). This possibility calls for further investigation of speleothems from the same cave.
We also investigated if the geochemical composition of the flood horizons has been affected by post depositional processes by comparing individual peaks downward along the growth axis, i.e. increasing age (Fig. 5). From this analysis it is not possible to detect any post depositional alteration of the clay layers.

\section{CONCLUSIONS/ RECOMMENDATIONS}

XRF scanning can be used to detect banding which is assumed to be related to floods in speleothems if these contain elements that are distinct from the carbonate matrix. XRF scanning of clay samples from the cave gave a good indication of which elements may be used as tracers for floods although more work is needed concerning the discrepancies in geochemical characteristics between cave clays and clay layers in the stalagmite. The results from this study show that petrographic thin sections may not be necessary to identify flood events recorded by speleothems. However, the XRF elemental data are highly sensitive to changes in geochemical composition over very short distances sometimes yielding multiple peaks for one flood horizon as seen in the thin section. Similarly, in areas with many flood horizons in close proximity there may be problems separating discrete peaks from a generally detrital (clay) affected matrix. In both cases petrographic thin sections may be needed to increase the precision in the analysis. Nevertheless, the number of thin sections that are needed will be reduced considerably. Geochemical biplots can be useful tools in defining discrete peaks and give valuable information about changes in the depositional history of the stalagmite. The distinct geochemical composition of the clay horizons presents a potential to use certain levels as marker horizons offering the possibility to chronologically tie different speleothems in a cave together.

\section{ACKNOWLEDGEMENTS}

The research has been carried out within the framework of the Navarino Environmental Observatory (NEO), Messinia, Greece, a cooperation between Stockholm University, the Academy of Athens and TEMES S.A. Mike Rogerson, University of Hull, was involved in the initial discussions leading to the creation of this paper. We thank the Ephorate of Palaeoanthropology and Speleology of Southern Greece for permitting visits to and sampling in Glyfada Cave and especially Yannis Bassiakos for introducing us to the cave. Joylon Desmarchelier and Ilias Liakopoulos assisted during sampling and field work. 
Miryam Bar-Matthews is acknowledged for processing the U-Th samples. Dan Zetterberg (Department of Geological Sciences) helped with cutting the stalagmite for thin section preparation. Grigoris Rousiotis provided information on recent floods. Ilias Liakopoulos also organized information from several people in Kapsia Village about historical floods of the cave. We thank Grégory Dandurand and three anonymous reviewers as well as Editor Dr. Bogdan P. Onac for input and comments that improved the manuscript.

\section{REFERENCES}

Borsato A., Frisia S., Fairchild I.J., Somogyi A. \& Susini J., 2007 - Trace element distribution in annual stalagmite laminae mapped by micrometer-resolution $X$-ray fluorescence: Implications for incorporation of environmentally significant species. Geochimica et Cosmochimica Acta, 71: 1494-1512. http://dx.doi.org/10.1016/j.gca.2006.12.016

Borsato A., Quinif Y., Bini A. \& Dublyansky Y., 2003 - Open-system alpine speleothems: implications for $U$-series dating and paleoclimate reconstructions. Studi Trentini di Scienze Naturali, Acta Geologica, 80: $71-83$

Brouwer N.P., 2006 - Theory of XRF- Getting Acquainted with the Principles, $2^{\text {nd }}$ ed., PANalytical B.V., Almelo, 71 p.

Croudace I.W., Rindby A. \& Rothwell R.G., 2006 ITRAX: description and evaluation of a new multifunction X-ray core scanner. In: Rothwell R.G. (ed.), New techniques in sediment core analysis. Geological Society Special Publication 267. London. Geological Society of London: 51-63. http://dx.doi.org/10.1144/GSL.SP.2006.267.01.04

Cui Y.F., Wang Y.J., Cheng H., Zhao K. \& Kong X.G., 2012 - Isotopic and lithologic variations of one precisely-dated stalagmite across the Medieval/LIA period from Heilong Cave, central China. Climate of the Past, 8: 1541-1550. http://dx.doi.org/10.5194/cp-8-1541-2012

Dandurand G., Maire R., Ortega R., Devès G., Lans B., Morel L., Perroux A.-S., Vanara N., Bruxelles L., Jaillet S., Billy I., Martinez P., Ghaleb B. \& Valla F., 2011 - X-ray fluorescence microchemical analysis and autoradiography applied to cave deposits: Speleothems, detrital rhythmites, ice and prehistoric paintings [Analyses microchimiques par fluorescence $X$ et autoradiographie appliquées aux dépôts de grotte: Spélé othèmes, rythmites détritiques, glace et peintures rupestres]. Geomorphologie: Relief, Processus, Environnement, 4: 407-426.

Dasgupta S., Saar M.O., Edwards R.L., Shen C.-C., Cheng H. \& Alexander E.C., 2010 - Three thousand years of extreme rainfall events recorded in stalagmites from Spring Valley Caverns, Minnesota. Earth and Planetary Science Letters, 300: 46-54. http://dx.doi.org/10.1016/j.epsl.2010.09.032
Dorale J.A., Lepley S.W. \& Edwards R.L., 2005 - The ultimate flood recorder: flood deposited sediments preserved in stalagmites. Geophysical Research Abstracts, 7: 09901.

Finné M., Bar-Matthews M., Holmgren K., Sundqvist H. S., Liakopoulos I. \& Zhang Q., 2014 - Speleothem evidence for late Holocene climate variability and floods in Southern Greece. Quaternary Research, 81: 213-227. http://dx.doi.org/10.1016/j.yqres.2013.12.009

Ford D.C. \& Williams P.W., 1989. Karst Geomorphology and Hydrology. Unwin Hyman, London: 601 p.

Frisia S., Borsato A., Fairchild I.J. \& Susini J., 2005 Variations in atmospheric sulphate recorded in stalagmites by synchrotron micro-XRF and XANES analyses. Earth and Planetary Science Letters, 235: 729-740.

Higgins M.D. \& Higgins R.A., 1996 - A geological companion to Greece and the Aegean. Duckworth, London, 240 p.

Kylander M.E., Ampel L., Wohlfarth B. \& Veres D., 2011 - High-resolution X-ray fluorescence core scanning analysis of Les Echets (France) sedimentary sequence: New insights from chemical proxies. Journal of Quaternary Science, 26: 109-117. http://dx.doi.org/10.1002/jqs.1438

Kylander M.E., Lind E.M., Wastegård S. \& Löwemark L., 2012 - Recommendations for using XRF core scanning as a tool in tephrochronology. Holocene, 22: 371-375. http://dx.doi.org/10.1177/0959683611423688

Lewin J. \& Woodward J.C., 2009 - Karst geomorphology and environmental change. In: Woodward J.C. (ed), The physical geography of the Mediterranean. Oxford: Oxford University Press: 287-317.

Lowe D.J., 2011 - Tephrochronology and its application: A review. Quaternary Geochronology, 6: 107-153. http://dx.doi.org/10.1016/j.quageo.2010.08.003

Merdenisianos C., 2005 - The cave of Kapsia at Mantinia and its anthropological findings. In: Proceedings of the $14^{\text {th }}$ International Congress of Speleology, AthensKalamos, Greece. Athens: Hellenic Speleological Society: 230-232.

Palmer A.N., 1991 - Origin and morphology of limestone caves. Geological Society of America Bulletin, 103: 1-21. http://dx.doi.org/10.1130/00167606(1991)103<0001:OAMOLC>2.3.CO;2

Riethdorf J.-R., Nürnberg D., Max L., Tiedemann R., Gorbarenko S.A. \& Malakhov M.I., 2013 - Millennialscale variability of marine productivity and terrigenous matter supply in the western Bering Sea over the past 180 kyr. Climate of the Past, 9: 1345-1373. http://dx.doi.org/10.5194/cp-9-1345-2013

Wu J.Y., Wang Y.J., Cheng H., Kong X.G. \& Liu D.B., 2012 - Stable isotope and trace element investigation of two contemporaneous annually-laminated stalagmites from northeastern China surrounding the $8.2 \mathrm{ka}$ event. Climate of the Past, 8: 1497-1507. http://dx.doi.org/10.5194/cp-8-1497-2012 